\title{
PARTICLE SIZE, SPATIAL VARIATIONS, AND POLLUTION SOURCE APPORTIONMENT OF STREET DUST FROM A TYPICAL INDUSTRIAL DISTRICT, IN WUHAN, CHINA
}

\author{
LI, K. J. ${ }^{1,2}-$ ZHU, X. ${ }^{1,2^{*}}-$ YU, W. X. ${ }^{1,2}-$ YU, Y. N. ${ }^{1,2}$ \\ ${ }^{I}$ Research Center for Environment and policy, Zhongnan University of Economics and Law, \\ Wuhan 430073, China \\ ${ }^{2}$ School of Information and Safety Engineering, Zhongnan University of Economics and Law, \\ Wuhan 430073, China \\ Corresponding author \\ e-mail: zhuxi@zuel.edu.cn
}

(Received $27^{\text {th }}$ Sep 2019; accepted $4^{\text {th }}$ Feb 2020)

\begin{abstract}
To analyse the spatial distribution patterns and sources of heavy metals $(\mathrm{Cr}, \mathrm{Cu}, \mathrm{Ni}, \mathrm{Zn}), 25$ road dust samples were collected from a typical industrial area of Wuhan in July 2017. The multivariate statistics, geostatistics, and the field source survey were adopted to study the sources and pollution pattern of studied metals. The results indicated that the concentration distribution of heavy metals was related to dust particle size and pollution source. Cr had high spatial aggregation in QD, could be concentrated easily in 63-150 $\mu \mathrm{m}$ dust, and was discharged by industrial sources. $\mathrm{Cu}, \mathrm{Zn}$, and $\mathrm{Ni}$ were also enriched in 63-150 $\mu \mathrm{m}$ dust. $\mathrm{Cu}$ had high spatial aggregation in less than $45 \mu \mathrm{m}$ and was derived from building construction sources. $\mathrm{Zn}$ and $\mathrm{Ni}$ were concentrated in 63-150 $\mu \mathrm{m}$ and originated from traffic sources and building construction sources. Pollution source influenced particle size and the content and distribution pattern of different heavy metals in atmospheric sediments, but the influence had obvious spatial limitations and compound effects.
\end{abstract}

Keywords: Moran's I, heavy metal, ArcGIS, PMF, atmospheric sediments

\section{Introduction}

The heavy metal contamination, such as $\mathrm{Cr}, \mathrm{Ni}, \mathrm{Cu}, \mathrm{Pb}, \mathrm{Zn}$, and $\mathrm{Cd}$, are high in urban soils and road dust (RD) in developed and industrial cities, and the pollution level of heavy metals in urban RD is usually much higher than that in urban soil (Wei and Yang, 2010; Chen et al., 2011) RD can easily enter the human body through uptake, absorption, and skin absorption, thereby threatening human health. RD also easily affects the urban environment quality through the hydrological cycle and atmospheric circulation. The damage is often hidden, potent, and long-term (Dockery and Pope, 1994; Sadiq et al., 1994; Crosby et al., 2006; Aelion et al., 2008; Wei et al., 2009, 2010; Wei and Yang, 2010; Sun et al., 2014). In China, most of the cities are dusty because a lot of infrastructures and buildings are under construction. Extensive research has been made on the human health risks and environmental ecological risks of heavy metals in urban $\mathrm{RD}$, but the evaluation system of heavy metals in RD remains imperfect compared to soil standards (Soltani et al., 2015; Huang et al., 2016; Jayarathne et al., 2018). Heavy metal contamination in dust has obvious regional characteristics and mutable distribution and is interfered by many complicated pollution sources (Liang et al., 2011; Sun et al., 2014; Li et al., 2015, 2017; Dehghani et al., 2017; Škrbić et al., 2018; Alsubaie et al., 2019). The identification of heavy metal sources of RD is beneficial to risk management and control, and it can provide a theoretical basis for the uniform evaluation of dust pollution. 
Sources of heavy metals in RD are always classified into anthropogenic and natural sources. Anthropogenic sources include traffic pollution, industrial activities, and demolition or construction. Natural sources are mainly from secondary blowing dust of adjacent soils in the streets (Amato et al., 2009; Soltani et al., 2015). Heavy metals are greatly affected by different pollution sources (such as $\mathrm{Pb}, \mathrm{Cu}, \mathrm{Zn}, \mathrm{As}, \mathrm{Mo}, \mathrm{Ni}$, and $\mathrm{Ti}$ ), industrial sources, and ground dust; $\mathrm{Ni}$ is mostly derived from alloy manufacturing; $\mathrm{Cd}$, $\mathrm{Hg}, \mathrm{Zn}, \mathrm{Fe}, \mathrm{Ba}, \mathrm{Cu}$, and $\mathrm{Pb}$ are mainly from vehicle traffic sources; $\mathrm{Zn}$ and $\mathrm{Fe}$ always come from multiple tires; $\mathrm{Ba}, \mathrm{Cu}, \mathrm{Fe}, \mathrm{Pb}$, and $\mathrm{Zr}$ are mostly derived from brake wear (Christoforidis and Stamatis, 2009; Soltani et al., 2015; Dehghani et al., 2017; Valotto et al., 2018; Urrutia-Goyes et al., 2018). Compared with point source pollution, such as industrial activities and dust removal at demolition or construction sites, traffic pollution has nonpoint source characteristics. Traffic density has a significant impact on RD and heavy metals and has regional characteristics. For instance, the concentration of heavy metals in the dust of Zhengzhou Branch Road is the highest, whereas the secondary trunk road has the lowest concentration. However, no obvious law exists on the concentration of heavy metals in RD of different sizes in Beijing. Among them, $\mathrm{Ni}, \mathrm{Cu}, \mathrm{Zn}, \mathrm{Cr}, \mathrm{Pb}$, and $\mathrm{Cd}$ are affected by traffic (Shen et al., 2018). The heavy metal content in the dust on both sides of roads decreases exponentially with an increase in distance from highways, and it is affected by traffic flow, vehicle type, terrain and road conditions, green belt configuration, and wind and rainfall conditions (Guo et al., 2008). $\mathrm{Pb}$ and $\mathrm{Zn}$ often exist in the dust, and the $\mathrm{Zn}$ concentration is always high due to traffic pollution (Long et al., 2015). The measurement of traffic pollution always focuses on the division of main and secondary roads. Nevertheless, traffic volume can directly reflect the degree of traffic pollution because of the traffic congestion section and the main roads do not overlap completely in China.

The source identification of $\mathrm{RD}$ is complex because of the variation in regional features, the unstable influence of sources, and the unstable characteristics of components. For example, $\mathrm{Zn}, \mathrm{Cr}$, and $\mathrm{Pb}$ in Shanghai's surface dust are mainly concentrated in particles smaller than $75 \mu \mathrm{m}$, followed by $75-150 \mu \mathrm{m}$ (Wang et al., 2009). Similarly, the heavy metals in the street dust of the old town of Zhenjiang City decrease with particle size, and the heavy metal content shows a highly progressive tendency (Xu et al., 2012). $\mathrm{Cu}, \mathrm{Pb}, \mathrm{Zn}$, and $\mathrm{Cr}$ in the street dust of Xuchang City are remarkably correlated with 50-100 $\mu \mathrm{m}$ coarse silt, whereas $\mathrm{Mn}$ and $\mathrm{Ni}$ are highly correlated with 10-50 $\mu \mathrm{m}$ fine silt. Nonetheless, their content does not follow grain size. Co has a strong correlation with the component of clay smaller than $10 \mu \mathrm{m}$, and its particle size distribution is prominent (Yan et al., 2016).

An interaction occurs between the contamination of heavy metal and the grain size distribution of urban dust. For instance, $\mathrm{Cu}$ and $\mathrm{Zn}$ in the surface dust of a middle school in the Datong mining area are mainly concentrated in coarse particles, but no significant difference exists in Pd and Cd enrichment at different grain levels (Guo et al., 2013). The heavy metals in the construction site of Guiyang City indicate the largest fine particle enrichment (exceeding 40\%) in all areas, whereas the coarse particle enrichment is the lowest (Liu et al., 2017). The particle size distributions of $\mathrm{Cd}$ and $\mathrm{Cu}$ in Luoyang City are obvious in densely populated areas, and $\mathrm{Cd}$ enrichment tends to be fine (75-96 and $75 \mu \mathrm{m})$. The mass fraction of $\mathrm{Cu}$ in $150-180 \mu \mathrm{m}$ increases rapidly, and the particle size decreases and peaks at $75 \mu \mathrm{m}$. $\mathrm{Zn}$ is mainly concentrated in the $150-180 \mu \mathrm{m}$ particle size in the traffic congestion zone, whereas $\mathrm{Pb}$ only has the grain size effect in the industrial zone (Li et al., 2018). However, in the process of rapid urban development in China, many 
cities have no strict boundary lines in commercial, industrial, residential, and transportation areas. The division of areas is difficult to equate with pollution sources. The effect of particle size of heavy metals in the dust on the study area cannot directly explain the law among pollution sources, particle size, and heavy metal.

From the preceding analysis, this study aims to investigate the sources of RD heavy metals in Qingshan District (QD) in Wuhan City, which is an old industrial area of developed cities. This study analyzes the correlation between heavy metal concentration and particle size of dust by ArcGIS and Moran's index (Moran's I). We discuss the relationship between grain size classification and pollution source and distinguish the main source of heavy metals in dust in the effective particle size range with the positive matrix factorization (PMF)-Environmental Protection Agency (EPA) method. This study reveals the interaction between heavy metal pollution in dust and pollution sources and particle size segments in a typical industrial city area under development and provides important data support and research reference to prevent and control RD heavy metal pollution in industrial cities.

\section{Materials and methods}

\section{Study area and sample collection}

QD covers an area of nearly $80.47 \mathrm{~km}^{2}$ and is located in Wuhan City, Hubei Province, China. This old industrial area is built up around the Wuhan Iron and Steel Company, which is the fourth largest enterprise company in the world's steel industry, and has more than 5.4 million inhabitants. QD has a continental climate, with cool winters and hot summers. Winter lasts from mid-December to mid-March with southeast winds, whereas summer lasts from mid-June to mid-September with northwest winds. Twenty-five RD samples were collected by mesh points and expert point method. The sample plot was selected beside the main road, crossroads, and overpass from 25 different locations in QD during the summer (July 2017), as shown in Fig. 1 and the original data is shown in Table 1. The sampling process was completed throughout the day of low wind speed $(1.6 \mathrm{~m} / \mathrm{s}-5.5 \mathrm{~m} / \mathrm{s})$, within 3 days after several days without any rain. One sample area contained multiple points and a plot area of $1 \mathrm{~m}$ width by the distance from the curb to the road centerline was demarcated at each study site to ensure the representative collection of solids distributed across the road surface (Christoforidis and Stamatis, 2009; Urrutia-Goyes et al., 2018; Shen et al., 2018). Plastic brushes were used to sweep RD up into a locked plastic bag. A cotton cloth was used to clean tools after sampling to avoid cross-contamination. Each sample of 500-1000 g of street dust (surface atmospheric sediments on cement road) was separated by a $2000 \mu \mathrm{m}$ stainless steel sieve using a diagonal line method at a distance of a few centimeters away on the curb. The samples needed sufficient quality (500-1000 g) to classify particle size. Subsequently, the composite samples were thoroughly mixed and air-dried. Approximately $150 \mathrm{~g}$ of dust was dispersed in rotary vibration (BZS-200DC) and investigated by the weighing method to characterize the particle size distributions. Samples were sieved into six stages (more than 500, 500-250, 250-150, 150-63, 63-45, and less than $45 \mu \mathrm{m}$ ) as subsamples for the following experiment. These particle size ranges were selected in view of their significance in metal-solid adsorption and health risk characteristics, which can lead to variable contamination levels (Chang et al., 2009; Karmacharya and Shakya, 2012; Shi et al., 2018). 


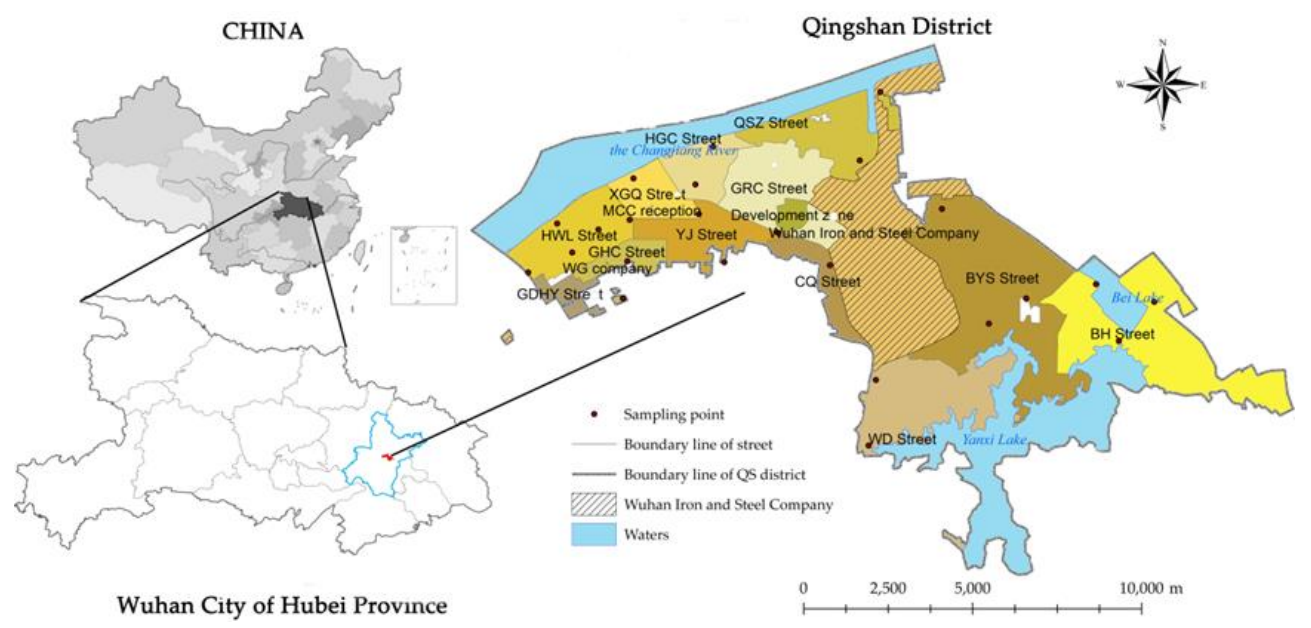

Figure 1. Sampling sites of RD in Qingshan

Table 1. Original data and pollution sourcesof samplings sites

\begin{tabular}{|c|c|c|c|c|c|}
\hline Sample & $\begin{array}{c}\text { Temperature } \\
\left({ }^{\circ} \mathrm{C}\right)\end{array}$ & $\begin{array}{c}\text { Relative humidity } \\
(\%)\end{array}$ & Longitude & Latitude & Pollution type \\
\hline S1 & 30 & 76 & E 114.359269 & N 30.616601 & Construction \\
\hline S2 & 30 & 76 & E 114.370969 & N 30.621926 & \\
\hline S3 & 31 & 72 & E 114.366978 & N 30.6296021 & Construction \\
\hline S4 & 31 & 72 & E 114.378029 & N 30.628009 & Construction \\
\hline S5 & 32 & 66 & E 114.385662 & N 30.619633 & \\
\hline S6 & 32 & 66 & E 114.387434 & N 30.612799 & \\
\hline S7 & 32 & 66 & E 114.387330 & N 30.641614 & \\
\hline S8 & 32 & 66 & E 114.386313 & N 30.630564 & Construction \\
\hline S9 & 32 & 69 & E 114.404692 & N 30.632067 & \\
\hline S10 & 33 & 64 & E 114.411466 & N 30.619275 & \\
\hline S11 & 32 & 66 & E 114.403818 & N 30.639964 & \\
\hline S12 & 32 & 69 & E 114.408505 & N 30.650025 & \\
\hline S13 & 32 & 66 & E 114.424812 & N 30.645168 & \\
\hline S14 & 33 & 63 & E 114.425704 & N 30.627187 & Construction \\
\hline S15 & 33 & 64 & E 114.439614 & N 30.618538 & Industry \\
\hline S16 & 33 & 64 & E 114.450361 & N 30.641438 & Industry \\
\hline S17 & 33 & 64 & E 114.452973 & N 30.664559 & \\
\hline S18 & 30 & 74 & E 114.44762997 & N 30.589838244 & \\
\hline S19 & 29 & 75 & E 114.44991619 & N 30.570565216 & Construction \\
\hline S20 & 33 & 62 & E 114.48188679 & N 30.603038834 & Construction \\
\hline $\mathrm{S} 21$ & 33 & 66 & E 114.46939278 & N 30.633547111 & \\
\hline S22 & 34 & 62 & E 114.52586251 & N 30.608796659 & Industry \\
\hline S23 & 34 & 62 & E 114.49180857 & N 30.609703891 & \\
\hline S24 & 34 & 62 & E 114.5165 & N 30.598442 & Industry \\
\hline S25 & 33 & 62 & E 114.5104 & N 30.6135 & Industry \\
\hline
\end{tabular}

\section{The field source survey}

In the data statistics process, we counted the local traffic flow three eight-hour shifts per day, in several sample collecting days. According to the Public Safety Industry Standards of the People's Republic of China, Road Traffic Congestion Degree, and Evaluation Method, we give value to various traffic conditions into 4 levels. In addition, population density (Appendix Table 1) is collected by China Statistical Yearbook, industry pollution and construction pollution statistics are from a field visit, both are shown in Table 1. 


\section{Chemical analysis}

Approximately $500 \mathrm{mg}$ of each subsample was weighed with an analytical balance of nominal sensitivity of $0.01 \mathrm{mg}$ and digested by an electric hot plate (5:5:3 nitric acid, hydrofluoric acid, and perchloric acid). All digested samples were then stored in Teflon bottles. The digested and properly diluted samples were analyzed with an atomic absorption spectrophotometer (AAS; ZEEnit-700P). Cu, Cr, Zn, and Ni were analyzed by flame method.

The content of heavy metals used in this study was calculated by Equation (1) to eliminate the diversity in dust's content in different particle sizes. In the formula, $\mathrm{C}_{1 \mathrm{i}}$ represents the heavy metal content of one grain-size segment in the dust sample $(\mathrm{mg} / \mathrm{kg})$, $\mathrm{C}_{0 \mathrm{i}}$ is the concentration analyzed by the AAS $(\mathrm{mg} / \mathrm{kg}), \mathrm{m}_{1 \mathrm{i}}(\mathrm{g})$ is the mass of the entire dust sample, $\mathrm{m}_{2 \mathrm{i}}(\mathrm{g})$ is the mass of dust of the grain-size segment, and $\mathrm{i}$ represents the sampling points.

$$
C_{1 i}=C_{0 i} \times \frac{m_{2 \mathrm{i}}}{m_{1 \mathrm{i}}}
$$

\section{Receptor models}

\section{Moran's I}

The global Moran's I method has been widely used to reflect the degree of spatial autocorrelation, spatial agglomeration, and distribution divergence. Moran's I was calculated by the following Equation (2):

$$
I=\frac{n \sum_{i=1}^{n} \sum_{j=1}^{n} w_{i, j}\left(D_{i}-\bar{D}\right)\left(D_{j}-\bar{D}\right)}{\sum_{i=1}^{n} \sum_{j=1}^{n} w_{i, j}\left(D_{i}-\bar{D}\right)^{2}}
$$

where $\mathrm{i}$ and $\mathrm{j}$ are the $\mathrm{ith}$ and $\mathrm{jth}$ sampling points, respectively; $\mathrm{D}$ represents the concentration of heavy metals; and $\mathrm{W}_{\mathrm{i}, \mathrm{j}}$ is a matrix of spatial weights. The global Moran's I value range is $[-1,1]$. A positive value indicates the spatial agglomeration distribution, whereas a negative value indicates the spatial divergence distribution. High Moran's I values indicate a strong spatial structure, whereas low Moran's I values indicate weak spatial structure. Zeroes represent random spatial distributions, i.e., no spatial correlation.

\section{$P M F$}

PMF has been applied in the source apportionment of various pollutants in the atmosphere, soil, and dust (Cao et al., 2015; Tian et al., 2018; Lv, 2019). PMF modeling was performed using the US-EPA PMF 5.0 program (Lv, 2019), which is a multivariate factor analysis tool. The initial data matrix $\mathrm{X}$ with the order of $\mathrm{m} \times \mathrm{n}$ can be expressed as Equation (3):

$$
\mathrm{X}=\mathrm{GF}+\mathrm{E}
$$

E can be written as Equation (4): 


$$
\mathrm{e}_{i j}=\sum_{k=1}^{p} g_{i k} f_{k j}-x_{i j}
$$

where $X_{i j}$ is the concentration of species $\mathrm{j}$ measured on sample $\mathrm{i}, \mathrm{p}$ is the number of factors contributing to samples, $g_{i k}$ is the relative contribution of factor k to sample i, $f_{i k}$ is the concentration of species $\mathrm{j}$ in source profile $\mathrm{km}$, and $e_{i j}$ is the error of the PMF model for species $\mathrm{j}$ measured on sample $\mathrm{i}$. The values of $g_{i k}$ and $f_{k j}$ are always positive and adjusted until a minimum $\mathrm{Q}$ value for a given $\mathrm{p}$ is found. The $\mathrm{Q}$ value can be expressed as Equation (5):

$$
Q=\sum_{i=1}^{n} \sum_{j=1}^{m}\left(\frac{e_{i j}}{u_{i j}}\right)^{2}
$$

where $u_{i j}$ is the uncertainty of the jth species concentration in the ith sample, $\mathrm{n}$ is the number of samples, and $\mathrm{m}$ is the number of species.

PMF requires the concentration of heavy metals and uncertainty files to run the model. The uncertainty is calculated based on the element-specific method detection limit (MDL), and error percent is measured by standard reference materials. All measured contents are above the MDL; therefore, the equations of uncertainty are adopted as follows:

If the concentration is less than or equal to the MDL used, then the uncertainty (Unc) is calculated using the following Equation (6):

$$
U_{n c}=\frac{5}{6} \times M D L
$$

If the concentration is greater than the MDL used, the uncertainty is calculated by Equation (7):

$$
U_{n c}=\sqrt{(\text { ErrorFraction } \times \text { concentration })^{2}+(0.5 \times M D L)^{2}}
$$

\section{Results}

\section{Granularity content}

The dust of each sampling point is graded and screened. The particle size distribution characteristics of dust are calculated by the gravimetric method, as shown in Table 2, which indicates the particle size distribution proportion. MAX/MIN means the weight of the sample in the specific particle size over the total weight in that size, which can characteristics of special points and reduce the error and judgment of the sorting and analysis of individual cases. AVG is the mass of each particle size segment is a percentage of the total dust mass, shown in Appendix Figure 1. The particle size distribution is generally not uniform and concentrates in the range of 63-150 (33\%), 150-250 (16\%), and $250-500 \mu \mathrm{m}(26 \%)$. The particle size with range below $45 \mu \mathrm{m}$ accounts for $1 \%-14 \%$, particulate matter $(\mathrm{PM})=45-63 \mu \mathrm{m}$ for $3 \%-14 \%, \mathrm{PM}=63-150 \mu \mathrm{m}$ for $19 \%-59 \%$, 
$\mathrm{PM}=150-250 \mu \mathrm{m}$ for $10 \%-27 \%, \mathrm{PM}=250-500$ for $10 \%-40 \%$, and $\mathrm{PM}>500 \mu \mathrm{m}$ for $3 \%-$ $25 \%$ of the total dust at each sampling site. The coefficient of variation increases gradually with the decrease in particle size when it is less than $63 \mu \mathrm{m}$. The regularity occurrence suggests that fine particles are vulnerable to local sources; this result is consistent with the study of $\mathrm{Xu}$, who showed that fine particles are enriched in heavy metals (Xu et al., 2012).

Table 2. Distribution of dust particle size

\begin{tabular}{c|c|c|c|c|c}
\hline Particle size $(\boldsymbol{\mu m})$ & AVG (\%) & MAX (\%) & MIN (\%) & SD (\%) & CV (\%) \\
\hline$>500$ & 11 & $25(\mathrm{~S} 11)$ & $0(\mathrm{~S} 17)$ & $6+-* / *_{-+}$ & 50 \\
$250-500$ & 26 & $41(\mathrm{~S} 17)$ & $13(\mathrm{~S} 14)$ & 7 & 25 \\
$150-250$ & 16 & $27(\mathrm{~S} 20)$ & $10(\mathrm{~S} 9)$ & 4 & 27 \\
$63-150$ & 33 & $59(\mathrm{~S} 24)$ & $19(\mathrm{~S} 23)$ & 8 & 26 \\
$45-63$ & 8 & $14(\mathrm{~S} 24)$ & $2(\mathrm{~S} 23)$ & 3 & 34 \\
$<45$ & 6 & $14(\mathrm{~S} 8)$ & $0(\mathrm{~S} 19-21)$ & 4 & 67 \\
\hline
\end{tabular}

\section{Pollution sources}

Particle size is a significant parameter which determines the environmental fate and the behavior of dust particles it has been found to be influential on the pollutant concentrations, while overestimation or underestimation would occur with improper strategies (Jayarathne et al., 2018). It is difficult to analysis of pollution sources precisely; the survey records can accurately reflect the current relationship between heavy metals in dust and pollution sources more than just Multivariate statistical analyses.

This study divides the pollution sources in QD into traffic, domestic, industrial, and building pollution sources (still under construction within one week of the sampling time), as shown in Fig. 2. The traffic source is considered from the vehicle speed, vehicle quantity, and residence time, and this study selects traffic flow as the index. According to GA115-1995 (Public Safety Industry Standards of the People's Republic of China, Road Traffic Congestion Degree, and Evaluation Method), the traffic pollution source is divided into four levels: speed not less than $30 \mathrm{~km} / \mathrm{h}$ is defined as smooth level (1\#), speed of $20-30 \mathrm{~km} / \mathrm{h}$ is defined as mild traffic (2\#), speed of $10-20 \mathrm{~km} / \mathrm{h}$ is defined as traffic jam (3\#), and speed less than $10 \mathrm{~km} / \mathrm{h}$ is defined as serious traffic jam (4\#). Traffic flow is obtained through collecting, arranging, and analyzing the data of the roads in QD for a long time. The main and secondary roads are highly congested in the northwest. The main roads, road traffic flow, and population density area do not overlap completely.
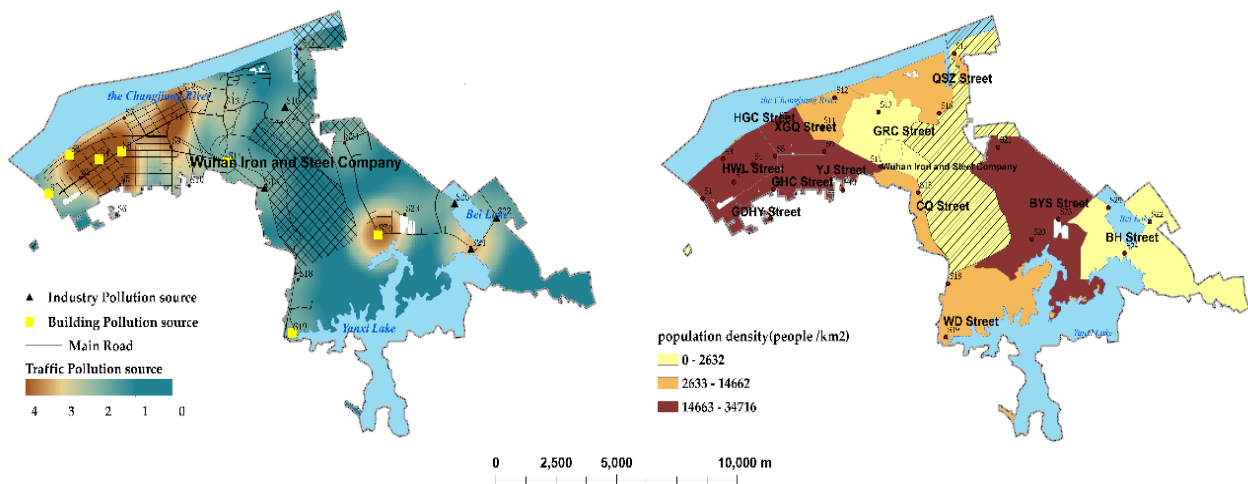

Figure 2. Distribution of dust pollution sources 
RD can contribute different PM10 rates in a different city area, the highest contributions were modeled in the commercial/residential district where most of the population live and work (Feng, 2016). The domestic pollution source measured by a population density responds to the frequency of human activities, such as waste disposal and cleaning. In this study, areas with population density between 14663 and 34716 people $/ \mathrm{km}^{2}$ are defined as a high-density zone, those between 2633 and 14662 people $/ \mathrm{km}^{2}$ are considered a mediumdensity zone (M zone), and those between 0 and 2632 people $/ \mathrm{km}^{2}$ are regarded as a lowdensity zone (L zone). Figure 2 shows that most areas of the domestic pollution source overlap onto traffic pollution sources. For example, BH Street is an L zone but a traffic jam area with frequent starts and stops of large engineering vehicles, whereas WD Street is an M zone but a smooth-level area because of remoteness and residents' habit.

The identification of industrial sources mainly includes all existing industrial plants in QD, such as the coking plant and micropower factory. However, the main plant of the Wuhan Iron and Steel Company is excluded because of closed management. Five industrial pollution sources exist around the company. This research identifies the construction sites as building pollution sources at the sampling period. Seven building pollution sources are scattered around Hongwei Street and an important intersection.

\section{Correlation between heavy metal distribution and grain size}

The average contents of $\mathrm{Cr}, \mathrm{Ni}, \mathrm{Cu}$, and $\mathrm{Zn}$ are 63.17, 26.49, 38.46, and $517.62 \mathrm{mg} / \mathrm{kg}$, respectively, which are over the corresponding soil background values by $0.73,0.71,1.25$, and 6.19 times, respectively. According to the background values of soil elements in China, Hubei (China National Environmental Monitoring Centre, 1990), $\mathrm{Cr}, \mathrm{Ni}, \mathrm{Cu}$, and $\mathrm{Zn}$ are $86,37.3,30.7$, and $83.6 \mathrm{mg} / \mathrm{kg}$, respectively. $\mathrm{Zn}$ is the main contaminant. The $\mathrm{Cr}$ contaminant ranges are 6.14-191.54, 6.11-45.97, 0.69-37.91, and $0.14-13.89 \mathrm{mg} / \mathrm{kg}$; the $\mathrm{Cu}$ contaminant ranges are 4.53-209.02, 6.07-73.49, 0.34-4.19, and 0.13-7.74 mg/kg; the $\mathrm{Ni}$ contaminant ranges are 7.4-39.0, 2.18-27.47, 1.15-6.21, and $0.15-9.80 \mathrm{mg} / \mathrm{kg}$; and the $\mathrm{Zn}$ contaminant ranges are 131.2-1537, 625.29-744.18, 8.37-133.89, and $1.01-68.35 \mathrm{mg} / \mathrm{kg}$. Cr, $\mathrm{Cu}, \mathrm{Zn}$, and $\mathrm{Ni}$ are all enriched in $63-150 \mu \mathrm{m}$.

The contamination distributions of $\mathrm{Cr}, \mathrm{Cu}, \mathrm{Ni}$, and $\mathrm{Zn}$ in different grain sizes (all sizes, 63-150, 45-63 $\mu \mathrm{m}$, and $<45 \mu \mathrm{m}$ ) are shown in Fig. 3, which is drawn by ArcGIS kernel density method. Density calculation is conducted for the heavy metals' concentration data of the sampling points, which form a corresponding raster layer (the obtained data are reduced by $10^{5}$ ) and present the trend of concentration in the search range. Spatial aggregation is measured by Moran's I model, as shown in Table 3. The contamination of $\mathrm{Cr}, \mathrm{Cu}, \mathrm{Ni}$, and $\mathrm{Zn}$ in different grain sizes presents varying distribution trends.

Cr pollution is mainly present in the particle sizes of 63-150 and 45-63 $\mu \mathrm{m}$ (Fig. 3a). Various positive correlation distributions are observed in different grain sizes. The distribution in all sizes is close to the cluster tendency gathering in Ganghuacun Street, Hongwei Road Street, and Beihu Street, and the spatial distribution is positive and relevant. The distribution in $63-150 \mu \mathrm{m}$ is similar to that in the all-size sample but more inclined to the random distribution, and the spatial distribution is positive but irrelevant. The distribution in 45-63 $\mu \mathrm{m}$ also presents cluster tendency but gathers in North Lake, and the spatial distribution is positively correlated and remarkable. The distribution in $<45 \mu \mathrm{m}$ shows cluster gathering in the streets of Hongwei Road, Xingouqiao, and the spatial distribution is positively correlated but unremarkable. Cr is generally concentrated in 45$63 \mu \mathrm{m}$, and the spatial aggregation is obvious and greatly affected by the influence of adjacent sources. 


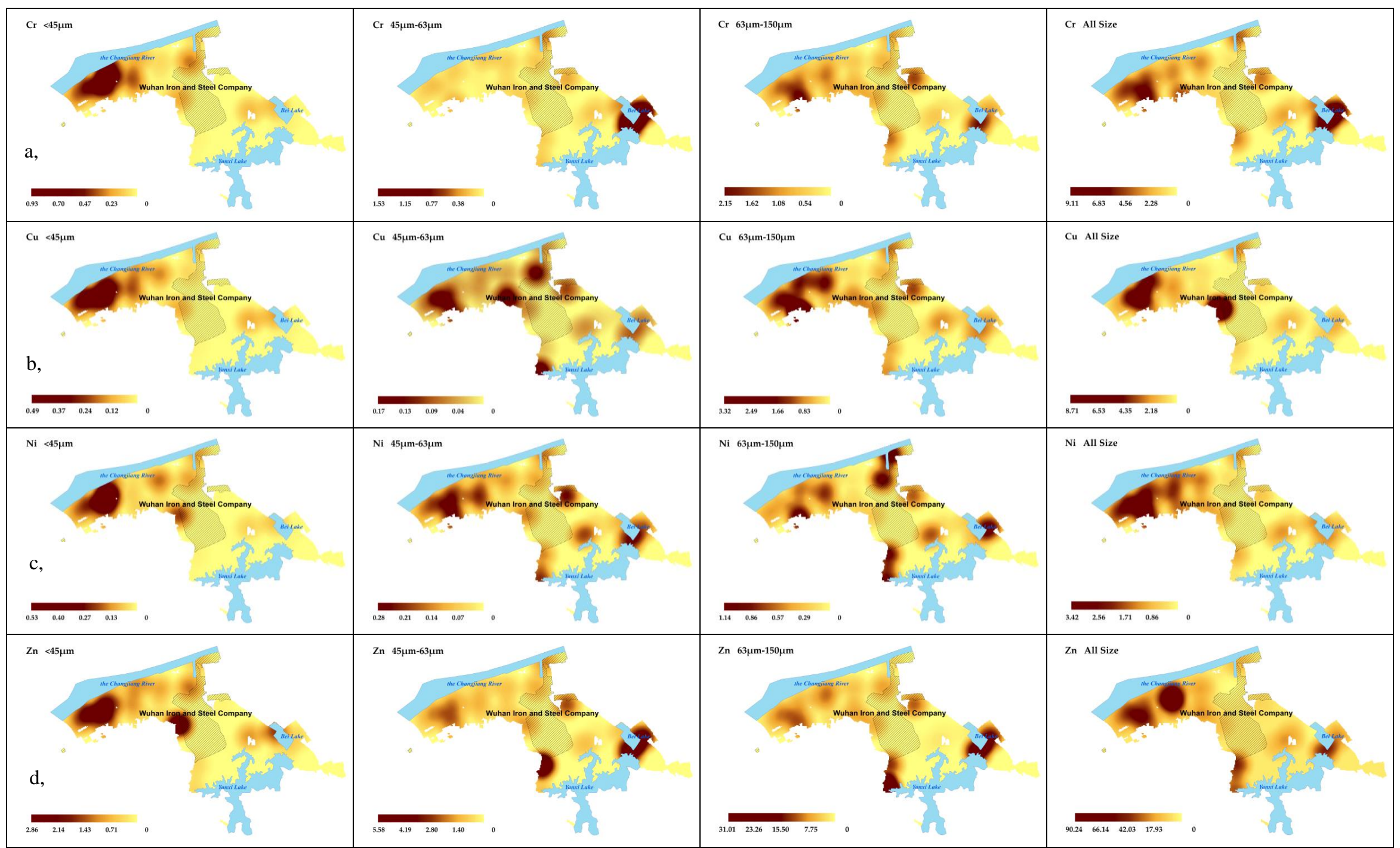

Figure 3. Distribution of heavy metal content in different sizes ( $a: \mathrm{Cr}, b: \mathrm{Cu}, \mathrm{c}: \mathrm{Ni}, \mathrm{d}: \mathrm{Zn})$

APPLIED ECOLOGY AND ENVIRONMENTAL RESEARCH 18(2):3331-3347.

http://www aloki.hu • ISSN 15891623 (Print) • ISSN 17850037 (Online)

DOI: http://dx.doi.org/10.15666/aeer/1802_33313347

(c) 2020, ALÖKI Kft., Budapest, Hungary 
Table 3. Moran's I of different heavy metal

\begin{tabular}{c|c|c|c|c|c}
\hline Heavy metal & Item & All Size & $\mathbf{6 3} \boldsymbol{\mu m - 1 5 0} \boldsymbol{\mu m}$ & $\mathbf{4 5} \boldsymbol{\mu m} \mathbf{- 6 3} \boldsymbol{\mu m}$ & $<\mathbf{4 5} \boldsymbol{\mu m}$ \\
\hline \multirow{3}{*}{$\mathrm{Cr}$} & Moran's I & 0.303725 & 0.218647 & 0.329085 & 0.179029 \\
& z-score & 2.196154 & 1.560779 & 2.362491 & 1.367709 \\
& p-value & 0.028081 & 0.118576 & 0.018153 & 0.171403 \\
\hline \multirow{3}{*}{$\mathrm{Cu}$} & Moran's I & 0.006938 & -0.073557 & 0.007967 & 0.464664 \\
& z-score & 0.442169 & -0.347610 & 0.372600 & 4.004758 \\
& p-value & 0.658367 & 0.728133 & 0.709446 & 0.000062 \\
\hline \multirow{3}{*}{$\mathrm{Ni}$} & Mora's In & 0.462726 & 0.309563 & 0.135859 & 0.060079 \\
& z-score & 3.930863 & 2.699898 & 1.348096 & 0.873931 \\
& p-value & 0.000085 & 0.006936 & 0.177628 & 0.382156 \\
\hline \multirow{3}{*}{$\mathrm{Zn}$} & Moran's I & -0.113302 & 0.088300 & 0.226290 & -0.071643 \\
& z-score & -0.603821 & 1.098097 & 2.221055 & -0.281705 \\
& p-value & 0.545962 & 0.272162 & 0.026347 & 0.778170 \\
\hline
\end{tabular}

$\mathrm{Cu}$ in the full-grain segment is distributed in the cluster and is mainly concentrated in Ganghuacun Street, Hongwei Road Street, and Changqian Street, with a P-value of 0.66 (Fig. 3b). The distribution is positively correlated but irrelevant. Cluster distribution occurs in $<45 \mu \mathrm{m} ; \mathrm{Cu}$ is distributed in Ganghuacun Street and Hongwei Road Street, and the spatial distribution is positively correlated and remarkable. The distribution in $45-63 \mu \mathrm{m}$ is random, and the spatial distribution is positively correlated but not prominent. Cluster distribution is observed in 63-150 $\mu \mathrm{m}$; it is mainly located in Ganghuacun Street, Hongwei Road Street, and Xingouqiao Street $(\mathrm{P}=0.73)$, and the spatial distribution is correlated positively but not significant. In summary, the spatial distribution of $\mathrm{Cu}$ is similar in different particle sizes. $\mathrm{Cu}$ accumulates in $63-150 \mu \mathrm{m}$, but the spatial distribution is relatively random.

$\mathrm{Ni}$ has different correlations in different particle size distributions (Fig. 3c). The Ni full-grain size segment is distributed in the cluster and is mainly concentrated in the streets of Hongwei Road and Ganghuacun, with a positively correlated and significant spatial distribution. Ni is clustered in $<45 \mu \mathrm{m}$ and concentrated in Hongwei Road Street with a normal phase but an insignificant spatial distribution. RD of 45-63 $\mu \mathrm{m}$ represents the random distribution, and the spatial distribution is positively correlated but unremarkable. Ni distribution in $63-150 \mu \mathrm{m}$ is also random, and the spatial distribution is positively correlated and relevant. Ni mainly has accumulated of $63-150 \mu \mathrm{m}$, and the degree of aggregation in the particle size segment is high.

The autocorrelation of $\mathrm{Zn}$ at different particle sizes is not high, but the difference is obvious (Fig. 3d). Zn in all sizes is clustered in Honggangcheng, Xingouqiao, and Hongwei Road streets with an insignificant negative correlation (the area of high concentration is adjacent to the area of low heavy metal concentration). RD distribution in $<45 \mu \mathrm{m}$ is cluster concentrated in Hongwei Road Street, Ganghuacun Street, and Changqian Street, with an insignificant negative correlation as well. The RD distribution in $45-63 \mu \mathrm{m}$ is random with a significantly positive correlation (the high concentration area is adjacent to the high heavy metal concentration area). The distribution is random in $63-150 \mu \mathrm{m}$, and the spatial distribution is positively correlated but insignificant. In general, the heavy metal $\mathrm{Zn}$ has a concentration characteristic in $63-150 \mu \mathrm{m}$, but the degree of aggregation is high in $45-63 \mu \mathrm{m}$.

$\mathrm{Zn}$ and $\mathrm{Ni}$ generally have a high degree of aggregation in $63-150 \mu \mathrm{m}$, but that of $\mathrm{Cr}$ is in $45-63 \mu \mathrm{m}$, whereas that of $\mathrm{Cu}$ is in less than $45 \mu \mathrm{m}$. This finding is consistent with several studies; e.g., heavy metals in surface dust are mainly concentrated in particle sizes 
of 75-150 $\mu \mathrm{m}$ (Shi and $\mathrm{Lu}, 2018$ ); heavy metals are easily enriched in small particles, especially in the range of 63-75 $\mu \mathrm{m}$; and $\mathrm{Cu}, \mathrm{Zn}$, and $\mathrm{Cr}$ are easy to concentrate in coarse silt $(63-150 \mu \mathrm{m})$ (Chang et al., 2009). The accumulation space is mainly concentrated in the northwest direction of QD (Hongwei Road Street and Gangdu Garden Street), Beihu Street, and Changqian Street. The distribution analysis of pollution sources also shows that the northwest direction is the area where traffic pollution is mainly concentrated, and relatively small industrial factories exist around Beihu Street. Changqian Street is near the Wuhan Iron and Steel Company, which is the largest factory in QD. The particle size of dust and its medium-heavy metal concentration is affected by adjacent sources of pollution. The influence of different heavy metals on varying particle sizes must be clarified. The concentration distribution and concentration level of heavy metals are relatively different, and pollution does not have the pattern of diffusion distribution around the main plant area of the Wuhan Iron and Steel Company. The distribution of heavy metals in urban dust has strong block limitations.

\section{Grain size distribution and pollution sources}

The dust at the sampling points of different pollution sources is counted in this study. The distribution of the maximum, minimum, and mean values of different particle fractions are discussed, and the contribution of pollution sources to dust particle size is analyzed. Figure 4 shows that the average amount of RD greater than $150 \mu \mathrm{m}$ is above $50 \%$, but heavy metal pollution is mostly concentrated in particles smaller than $150 \mu \mathrm{m}$. This condition is referred to as an effective heavy metal-enriched particle size segment. This segment is divided into particle sizes less than 45, 45-63, and 63-150 $\mu \mathrm{m}$ in accordance with the correlation of various metal contamination concentrations and particle sizes in the previous section. Different pollution sources have a spatial overlapping effect. For instance, the high-population-density area always has heavy traffic flow and building sources. By contrast, the industrial area is far away from the above source areas, and the influence of the industrial source on particle size has a high reference value.

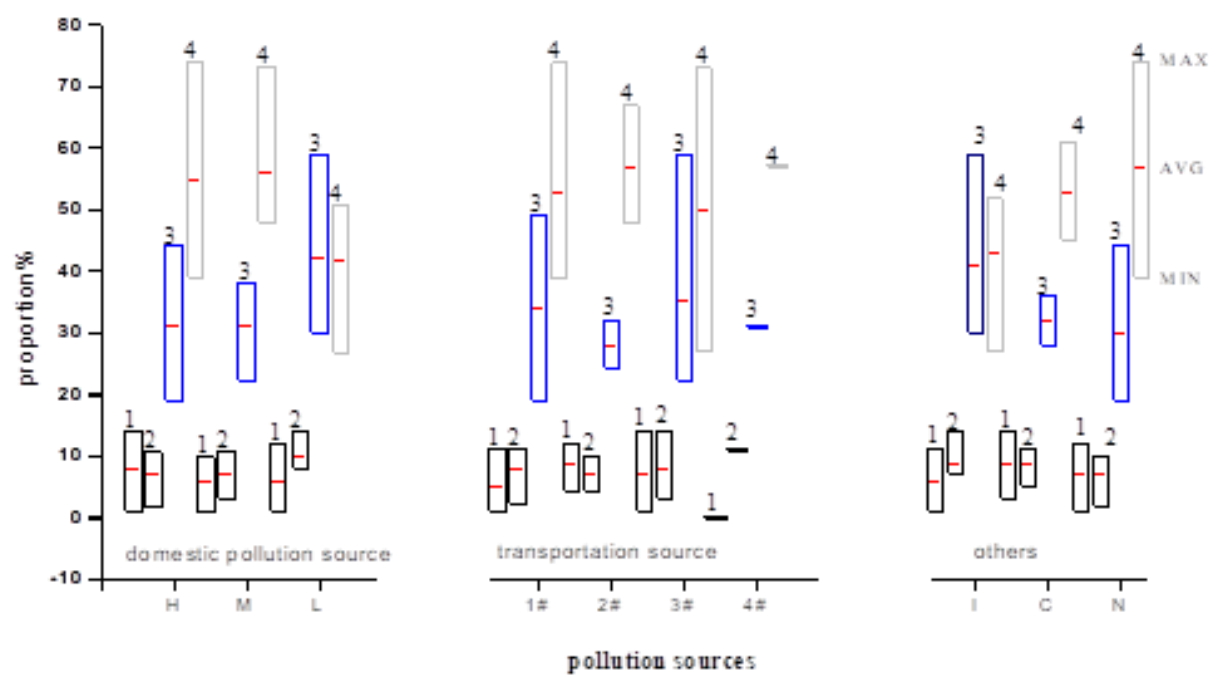

Figure 4. Map of contribution rate of pollution source to RD particle level (I means the industrial source; $C$ denotes the building source; $N$ indicates no pollution source; and 1, 2, 3, and 4 correspond to particle sizes of $\langle 45,45-63,63-150$, and $>150 \mu \mathrm{m}$, respectively) 
For particles smaller than 45 and 45-63 $\mu \mathrm{m}$, the maximum and minimum spans are small and unaffected by various sources. In comparison, high-density populations, low traffic flow, and building sources have a slight advantage in the $45 \mu \mathrm{m}$ average contribution rate, whereas low-density populations and high traffic flow have a slight advantage in 45-63 $\mu \mathrm{m}$. The maximum and minimum spans are greatly affected by pollution sources for the $63-150 \mu \mathrm{m}$ particle size segment. The industrial source mainly contributes to $63-150 \mu \mathrm{m}$, and the average value reaches $41 \%$. Particles near other pollution sources are in this particle size segment, and the mean is only $28 \%-35 \%$.

\section{Heavy metal and pollution source}

After PMF analyses of the sources of heavy metals in different particle sizes, the contribution rates of $\mathrm{Cr}, \mathrm{Cu}, \mathrm{Ni}$, and $\mathrm{Zn}$ of domestic pollution, transportation, building, and industrial sources are summarized (Fig. 5). Differences in sources of different types of heavy metal pollution in RD in QD are observed. Several studies have found that different heavy metals are greatly affected by different pollution sources; $\mathrm{Cu}, \mathrm{Cr}, \mathrm{As}, \mathrm{Mo}$, $\mathrm{Ni}$, and $\mathrm{Ti}$ are affected by industrial sources and ground dust from building operation; whereas $\mathrm{Cd}, \mathrm{Hg}, \mathrm{Zn}, \mathrm{Fe}, \mathrm{Ba}, \mathrm{Cu}$, and $\mathrm{Pb}$ are greatly affected by vehicle traffic sources (Soltani et al., 2015; Dehghani et al., 2017). We analyze the sources at different points.

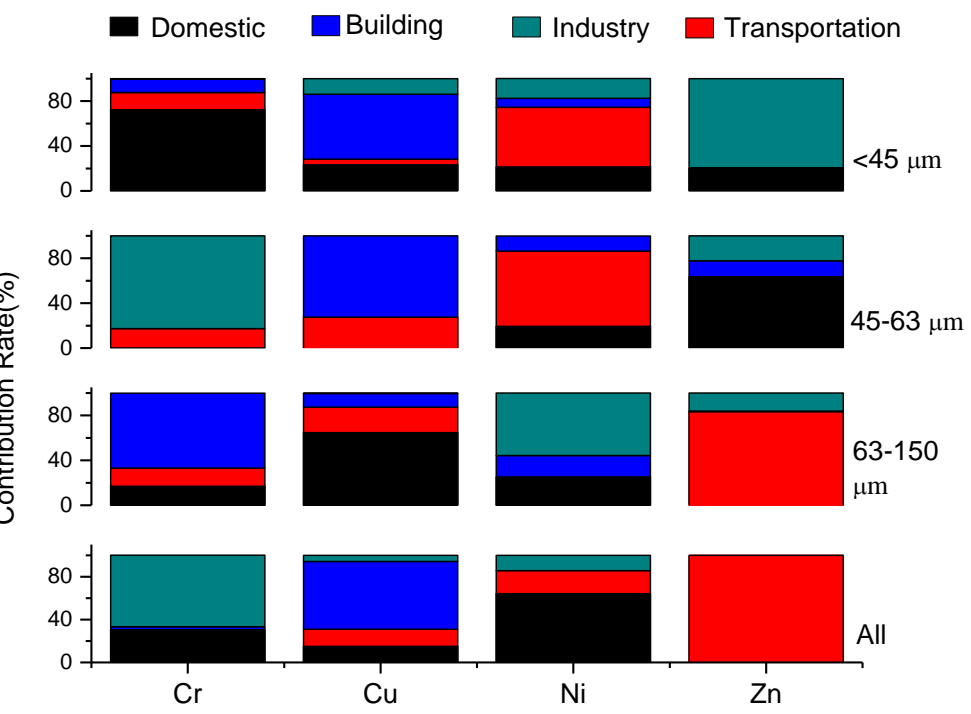

Figure 5. Correlation diagram of heavy metal concentration and pollution source in characteristic particle size

Industrial sources are the main sources of $\mathrm{Cr}$ and contribute to $45-63 \mu \mathrm{m}$ dust. $\mathrm{Cr}$ is highly attached to $45-63 \mu \mathrm{m}$ dust, so reducing the formation of $45-63 \mu \mathrm{m}$ dust is beneficial to the reduction of $\mathrm{Cr}$ in urban dust. Traffic sources have the highest contribution to grainlevel dust. On-site investigations indicate that large-scale transportation vehicles are frequent in such industrial active areas, with poor road conditions and large dust emission. Control of urban dust $\mathrm{Cr}$ pollution can be optimized by regulating pollution sources from car conditions, such as timely sprinklers and control of three waste emissions. Building pollution is the main source of $\mathrm{Cu}$ and contributes considerably to dust with a small particle size. The above analysis of construction sources contributes to dust with particle 
size less than $45 \mu \mathrm{m}$. The control of urban $\mathrm{Cu}$ pollution can reduce the formation of dust in urban construction. The source of $\mathrm{Ni}$ is relatively limited compared with that of $\mathrm{Cu}$, and all four contamination sources have certain contributions. Dust that is less than 63 $\mu \mathrm{m}$ is susceptible to traffic sources, whereas dust larger than $63 \mu \mathrm{m}$ is susceptible to industrial sources. In contrast to $\mathrm{Ni}, \mathrm{Zn}$ is highly affected by traffic sources, especially in large particle size segments (greater than $63 \mu \mathrm{m}$ ), and by industrial sources at less than $45 \mu \mathrm{m}$. Joint control of industrial and traffic sources can be considered for the formation of $\mathrm{Ni}$ and $\mathrm{Zn}$.

Different sources of pollution affect the amount and type of heavy metals, the differences can be observed in the distribution of particle size. The enrichment of heavy metals comes partly from the source discharge process, and other parts are from the process of contact with dust. Therefore, the concentration of heavy metals, pollution sources, and the particle sizes of dust are related. With the source control of different types and sizes of heavy metals in urban RD, dust pollution can be controlled in a targeted manner.

\section{Discussion}

Once we determined the sources related to various factors, the source contributions of heavy metals could be easily determined. PMF are widely used for the quantitative analysis of sources of various pollutants in the atmosphere, soil, and dust (Yang et al., 2017; Zhang et al., 2017; Duan et al., 2018; Garaga et al., 2018; Cai et al., 2019; Wang et al., 2019; Zhao et al., 2019). It can be used to calculate the source component spectrum and the contribution rate. Since the uncertainty is added in the calculation, the PMF can be used to solve the weighted factorization to achieve the individual processing of elements and reduce the requirements on the degree of connection between the data, making it suitable for analyzing complex pollution (Dong et al., 2019; Zhang et al., 2019). Khairy et al. found that PMF could afford better source apportionment of pollutants in the atmosphere, soils and sediments than APCS/MLR" (Jain et al., 2018). But The PMF method is unstable when directly used to describe dust sources (Cetin et al., 2018; Hu et al., 2018). The variation mainly stems from the differences in the volume of collected data and in the detection limits of the instruments used (Hu et al., 2018; Men et al., 2019) in this study, the result of the field source survey can match the regularity of PMF.

\section{Conclusion}

Our study analyzes the distribution and source of heavy metals in RD from the view of particle size distribution. The contributions of dust in 63-150, 45-63, and $<45 \mu \mathrm{m}$ sections are $33 \%, 8 \%$, and $6 \%$, respectively. $\mathrm{Cr}$ is enriched in $45-63 \mu \mathrm{m}$ with obvious spatial aggregation; $\mathrm{Cu}$ accumulates in $63-150 \mu \mathrm{m}$, but the spatial distribution is relatively random; Ni accumulates in 63-150 $\mu \mathrm{m}$ with obvious spatial aggregation, and $\mathrm{Zn}$ has a concentration characteristic in $63-150 \mu \mathrm{m}$, but the degree of aggregation is higher than that in $45-63 \mu \mathrm{m}$. The distribution of these heavy metals has strong limitations and is not only around the main plant area of the Wuhan Iron and Steel Company. It is necessary to add spatiotemporal analysis in the follow-up studies to further discuss this conclusion. The distribution is affected by nearby sources, including traffic, domestic, industrial, and building pollution sources, in this old industrial area. The dominant sources of heavy metals differ in varying particle sizes and heavy metals. The effective size of dust particles 
must be confirmed for accurate source assessment and effective management of dust pollution. For the PMF model, the number of samples in this paper is relatively small, so it is very necessary to increase the number of analysis samples in subsequent studies.

Funding Information. This study was financially supported by the Fundamental Research Funds for Central University administered by Zhongnan University of Economics and Law (Project No.: 2722019PY050), Science and Technology Project of Hubei Education Department (B2018551).

Conflict of Interests. The authors declare no conflict of interests.

\section{REFERENCES}

[1] Aelion, C. M., Davis, H. T., McDermott, S., Lawson, A. B. (2008): Metal concentrations in rural topsoil in South Carolina: potential for human health impact. - Science of the total environment 402(2-3): 149-156.

[2] Alsubaie, A., Alsulaiti, L., Al-Dabbous, A. N., Chamakh, M., Jaafar, M., Daar, E., Bradley, D. A. (2019): A comparison of elemental presence in Riyadh and Doha road dust. Radiation Physics and Chemistry 154: 58-63.

[3] Amato, F., Pandolfi, M., Viana, M., Querol, X., Alastuey, A., Moreno, T. (2009): Spatial and chemical patterns of PM10 in road dust deposited in urban environment. - Atmospheric Environment 43(9): 1650-1659.

[4] Cai, K., Li, C., Na, S. (2019): Spatial Distribution, Pollution Source, and Health Risk Assessment of Heavy Metals in Atmospheric Depositions: A Case Study from the Sustainable City of Shijiazhuang, China. - Atmosphere 10(4): 222.

[5] Cao, Z., Xu, F., Li, W., Sun, J., Shen, M., Su, X., Feng, J., Yu, G., Covaci, A. (2015): Seasonal and particle size-dependent variations of hexabromocyclododecanes in settled dust: implications for sampling. - Environmental science \& technology 49(18): 1115111157.

[6] Cetin, B., Yurdakul, S., Gungormus, E., Ozturk, F., Sofuoglu, S. C. (2018): Source apportionment and carcinogenic risk assessment of passive air sampler-derived PAHs and PCBs in a heavily industrialized region. - Science of The Total Environment 633: 30-41.

[7] Chang, J., Liu, M., Li, X., Lin, X., Wang, L., Gao, L. (2009): Primary research on health risk assessment of heavy metals in road dust of Shanghai. - China Environmental Science 29(5): 548-554.

[8] Chen, C. C., Lu, X. W., Wang, L. J., Lei, K. (2011): Health risk assessment of heavy metals in street dust in Baoji city. - Urban Environment \& Urban Ecology 24(2): 35-38.

[9] China National Environmental Monitoring Centre (1990): Background values of soil elements in China. - China Environmental Science Press 1990: 87-90, 330-496.

[10] Christoforidis, A., Stamatis, N. (2009): Heavy metal contamination in street dust and roadside soil along the major national road in Kavala's region, Greece. - Geoderma 151(34): 257-263.

[11] Crosby, D. G. (2006): Environmental Toxicology and Chemistry. - Oxford Univ. Press, 336p.

[12] Dehghani, S., Moore, F., Keshavarzi, B., Beverley, A. H. (2017): Health risk implications of potentially toxic metals in street dust and surface soil of Tehran, Iran. - Ecotoxicology and environmental safety 136: 92-103.

[13] Dockery, D. W., Pope, C. A. (1994): Acute respiratory effects of particulate air pollution. - Annual review of public health 15(1): 107-132.

[14] Dong, B., Zhang, R., Gan, Y., Cai, L., Freidenreich, A., Wang, K., Guo, T., Wang, H. (2019): Multiple methods for the identification of heavy metal sources in cropland soils from a resource-based region. - Science of the Total Environment 651: 3127-3138. 
[15] Duan, S., Zhou, Z., Liu, Y., Xiao, Y., Chen, P., Fan, C., Chen, S. (2018): Distribution and source apportionment of soil heavy metals in central-south of Hunan province. - Journal of Agricultural Science and Technology (Beijing) 20(6): 80-87.

[16] Feng, J., Hu, P., Li, X., Liu, S., Sun, J. (2016): Ecological and health risk assessment of polycyclic aromatic hydrocarbons (pahs) in surface water from middle and lower reaches of the yellow river. - Polycyclic Aromatic Compounds 36(5): 656-670.

[17] Garaga, R., Sahu, S. K., Kota, S. H. (2018): A review of air quality modeling studies in India: local and regional scale. - Current Pollution Reports 4(2): 59-73.

[18] Guo, G. H., Lei, M., Chen, T. B., Song, B., Li, X. Y. (2008): Effect of road traffic on heavy metals in road dust and roadside soils. - Acta Scientiae Circumstantiae 28(10): 1937-45.

[19] Guo, F., Sheng, H., Fan, W. (2013): Particle Size Distribution and health risk assessment of heavy metal of surface dust in middle school of mining district in Daton city. - Journal of Soil and Water Conservation 1: 162-166.

[20] Hu, W., Wang, H., Dong, L., Huang, B., Borggaard, O. K., Hansen, H. C. B., He, Y., Holm, P. E. (2018): Source identification of heavy metals in peri-urban agricultural soils of southeast China: an integrated approach. - Environmental pollution 237: 650-661.

[21] Hu, W., Day, D. A., Campuzano-Jost, P., Nault, B. A., Park, T., Lee, T., Croteau, P., Canagaratna, M. R., Jayne, J. T., Worsnop, D. R., Jimenez, J. L. (2018): Evaluation of the new capture vaporizer for Aerosol Mass Spectrometers (AMS): Elemental composition and source apportionment of organic aerosols (OA). - ACS Earth and Space Chemistry 2(4): 410-421.

[22] Huang, J., Li, F., Zeng, G., Liu, W., Huang, X., Xiao, Z., Wu, H., Gu, Y., Li, X., He, X., He, Y. (2016): Integrating hierarchical bioavailability and population distribution into potential eco-risk assessment of heavy metals in road dust: A case study in Xiandao District, Changsha city, China. - Science of the Total Environment 541: 969-976.

[23] Jain, S., Sharma, S. K., Mandal, T. K., Saxena, M. (2018): Source apportionment of PM10 in Delhi, India using PCA/APCS, UNMIX and PMF. - Particuology 37: 107-118.

[24] Jayarathne, A., Egodawatta, P., Ayoko, G. A., Goonetilleke, A. (2018): Assessment of ecological and human health risks of metals in urban road dust based on geochemical fractionation and potential bioavailability. - Science of the Total Environment 635: 16091619.

[25] Karmacharya, N., Shakya, P. R. (2012): Heavy metals in bulk and particle size fractions from street dust of Kathmandu city as the possible basis for risk assessment. - Scientific World 10(10): 84-88.

[26] Li, Y. Y., Li, Z. P., Xiong, H. L., Chen, Y. C., Dai, Y. (2015): Health risk assessment of street dust and heavy metal pollution in Chongqing. - Journal of Southwest University (Natural Science Edition) 37(2): 18-23.

[27] Li, H. H., Chen, L. J., Yu, L., Guo, Z. B., Shan, C. Q., Lin, J. Q., Zhu, X. M. (2017): Pollution characteristics and risk assessment of human exposure to oral bioaccessibility of heavy metals via urban street dusts from different functional areas in Chengdu, China. Science of the Total Environment 586: 1076-1084.

[28] Li, F., Zhang, J., Liu, W., Liu, J., Huang, J., Zeng, G. (2018): An exploration of an integrated stochastic-fuzzy pollution assessment for heavy metals in urban topsoil based on metal enrichment and bio accessibility. - Science of the total environment 644: 649-660.

[29] Liang, T., Shi, Z. T., Wu, F., Gu, X. M. (2011): Evaluation of heavy metal pollution and potential ecological risk in streets of Kunming. - Tropical Geography 31(2): 164-170.

[30] Liu, R., Tu, L. L., Gou, X., Yang, H. Y. (2017): Particle size distribution and health risk assessment of heavy metals of constructive dust in Guiyang. - Science Technology and Engineering 17(32): 187-195.

[31] Long, Y., Sun, C., Li, S., Liu, G. (2015): Comparative study on heavy metal pollution of surface dust in typical industries environment. - Environmental Engineering 02.

[32] Lv, J. (2019): Multivariate receptor models and robust geostatistics to estimate source apportionment of heavy metals in soils. - Environmental pollution 244: 72-83. 
[33] Men, C., Liu, R., Wang, Q., Guo, L., Miao, Y., Shen, Z. (2019): Uncertainty analysis in source apportionment of heavy metals in road dust based on positive matrix factorization model and geographic information system. - Science of The Total Environment 652: 2739.

[34] Sadiq, M., Mian, A. A. (1994): Nickel and vanadium in air particulates at Dhahran (Saudi Arabia) during and after the Kuwait oil fires. - Atmospheric Environment 28(13): 22492253.

[35] Shen, M. H., Dong, W. J., Wang, M. L., Yang, S., Yang, T. F., Tang, L. F., Cao, Z. G. (2018): Pollution characteristics of heavy metals in road dust and its relationship with road levels: Taking Beijing and Zhengzhou as examples. - Environmental Chemistry 05.

[36] Shi, D., Lu, X. (2018): Accumulation degree and source apportionment of trace metals in smaller than $63 \mu \mathrm{m}$ road dust from the areas with different land uses: A case study of Xi'an, China. - Science of the Total Environment 636: 1211-1218.

[37] Soltani, N., Keshavarzi, B., Moore, F., Tavakol, T., Lahijanzadeh, A. R., Jaafarzadeh, N., Kermani, M. (2015): Ecological and human health hazards of heavy metals and polycyclic aromatic hydrocarbons (PAHs) in road dust of Isfahan metropolis, Iran. - Science of the Total Environment 505: 712-723.

[38] Sun, Z. B., Zhou, J., Hu, B. B., Wang, Z. W., Meng, W. Q., Wang, Z. L. (2014): Characteristics of heavy metal pollution in urban street dust of Tianjin. - Ecol Environ Sci 23(1): 157-163.

[39] Škrbić, B. D., Buljovčić, M., Jovanović, G., Antić, I. (2018): Seasonal, spatial variations and risk assessment of heavy elements in street dust from Novi Sad, Serbia. - Chemosphere 205: 452-462.

[40] Tian, S., Liang, T., Li, K., Wang, L. (2018): Source and path identification of metals pollution in a mining area by PMF and rare earth element patterns in road dust. - Science of The Total Environment 633: 958-966.

[41] Urrutia-Goyes, R., Hernandez, N., Carrillo-Gamboa, O., Nigam, K. D. P., Ornelas-Soto, N. (2018): Street dust from a heavily-populated and industrialized city: Evaluation of spatial distribution, origins, pollution, ecological risks and human health repercussions. Ecotoxicology and environmental safety 159: 198-204.

[42] Valotto, G., Zannoni, D., Rampazzo, G., Visin, F., Formenton, G., Gasparello, A. (2018): Characterization and preliminary risk assessment of road dust collected in Venice airport (Italy). - Journal of Geochemical Exploration 190: 142-153.

[43] Wang, L., Liu, M., Ou, N., Chang, J., Xu, S. (2009): Particle size distribution of heavy metals in urban surface dusts in Shanghai. - Journal of East China Normal University (Natural Science) 6.

[44] Wang, S., Cai, L. M., Wen, H. H., Luo, J., Wang, Q. S., Liu, X. (2019): Spatial distribution and source apportionment of heavy metals in soil from a typical county-level city of Guangdong Province, China. - Science of The Total Environment 655: 92-101.

[45] Wei, B., Jiang, F., Li, X., Mu, S. (2009): Spatial distribution and contamination assessment of heavy metals in urban road dusts from Urumqi, NW China. - Microchemical Journal 93(2): 147-152.

[46] Wei, B., Yang, L. (2010): A review of heavy metal contaminations in urban soils, urban road dusts and agricultural soils from China. - Microchemical journal 94(2): 99-107.

[47] Wei, B., Jiang, F., Li, X., Mu, S. (2010): Contamination levels assessment of potential toxic metals in road dust deposited in different types of urban environment. - Environmental Earth Sciences 61(6): 1187-1196.

[48] Xu, W., Lv, B., Chu, J. Y. (2012): The particle size distribution and source apportionment of heavy metal contaminated street dusts in different functional district of Zhenjiang. Environmental Pollution \& Control 34(10): 32-33.

[49] Yan, H., Xiao, J., Zhang, J. L. (2016): Concentration and particle size effect of heavy metals in the street dust of Xuchang City. - Journal of Earth Environment 7(2): 183-191. 
[50] Yang, Y., Christakos, G., Guo, M., Xiao, L., Huang, W. (2017): Space-time quantitative source apportionment of soil heavy metal concentration increments. - Environmental pollution 223: 560-566.

[51] Zhang, Y., Cai, J., Wang, S., He, K., Zheng, M. (2017): Review of receptor-based source apportionment research of fine particulate matter and its challenges in China. - Science of the Total Environment 586: 917-929.

[52] Zhang, J., Li, R., Zhang, X., Bai, Y., Cao, P., Hua, P. (2019): Vehicular contribution of PAHs in size dependent road dust: A source apportionment by PCA-MLR, PMF, and Unmix receptor models. - Science of The Total Environment 649: 1314-1322.

[53] Zhao, L., Hu, G., Yan, Y., Yu, R., Cui, J., Wang, X., Yan, Y. (2019): Source apportionment of heavy metals in urban road dust in a continental city of eastern China: Using $\mathrm{Pb}$ and $\mathrm{Sr}$ isotopes combined with multivariate statistical analysis. - Atmospheric environment 201: 201-211.

\section{APPENDIX}

Table A1. Population density $/ \mathrm{km}^{2}$

\begin{tabular}{c|c}
\hline Street & Population density/km $\mathbf{k}^{\mathbf{2}}$ \\
\hline Honggang & 14662 \\
Beihu & 1024 \\
Baiyushan & 17688 \\
Yejin & 17444 \\
Qingshanzhen & 4352 \\
Gangduhuayuan & 32946 \\
Wudong & 3592 \\
Xingouqiao & 25647 \\
Gongrencun & 2632 \\
Ganghuacun & 34716 \\
Hongweilu & 20199 \\
Changqian & 3882 \\
\hline
\end{tabular}

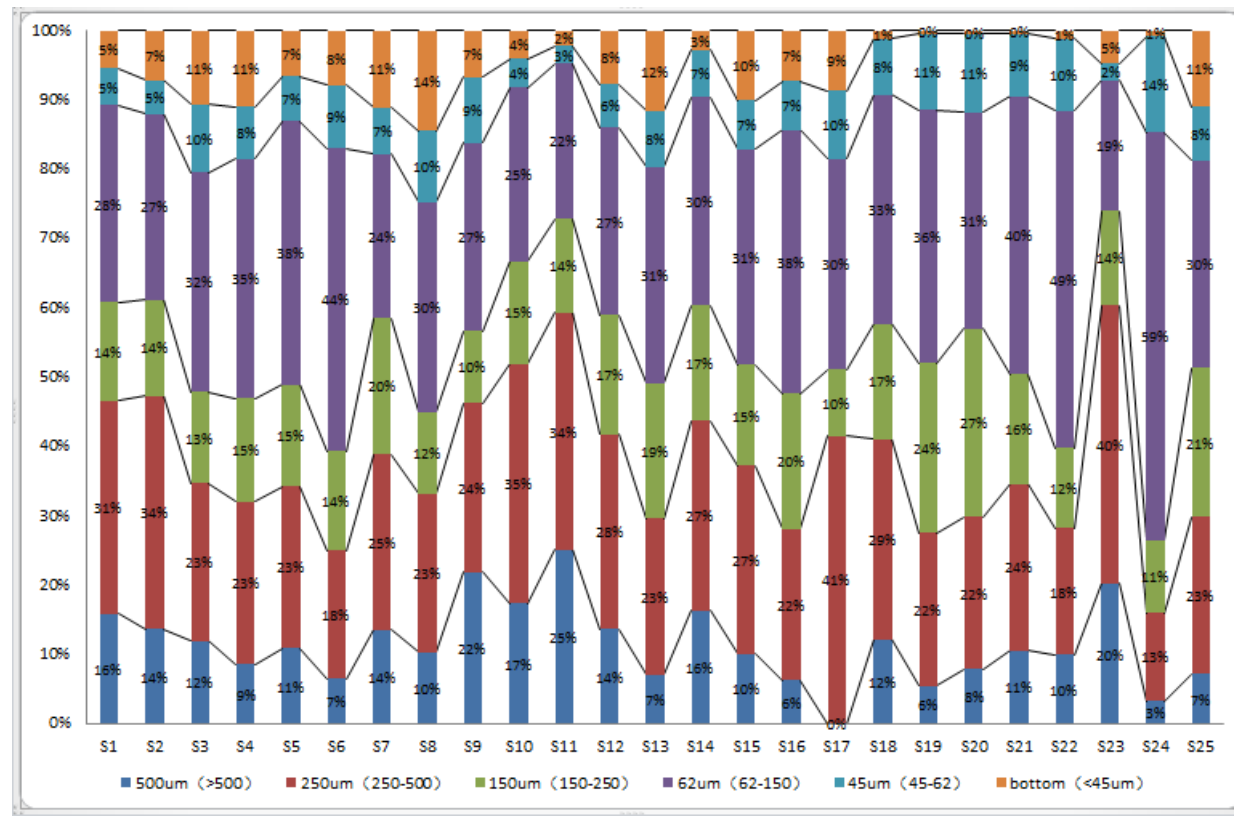

Figure A1. Original grain size distribution 